\title{
HISTÓRIAS EM QUADRINHOS E FICÇÃO CIENTÍFICA: ANÁLISE E PROPOSTA DE USO NO ENSINO DE CIÊNCIAS
}

\author{
COMICS AND SCIENCE FICTION: ANALYSIS AND PROPOSAL FOR USE IN \\ SCIENCE TEACHING
}

\author{
CÓMICS Y CIENCIA FICCIÓN: ANÁLISIS Y PROPUESTA DE USO EN LA \\ ENSEÑANZA DE LAS CIENCIAS
}

\author{
Luciano Calixto de Sousa Junior* (D) 9 \\ Tatiana Galieta $^{* *}$ (iD) ()
}

\begin{abstract}
RESUMO
As histórias em quadrinhos (HQs) são um recurso eficiente como incentivo à leitura, além de um importante auxiliar no ensino de Ciências, mostrando-se capazes de promover a interdisciplinaridade entre os conteúdos curriculares e a extrapolação imaginária pelos alunos. Partindo desse pressuposto, este artigo relata uma pesquisa em que foi feita uma análise documental das minisséries "Dinastia X" e "Potências de X", dos X-Men, por meio da identificação dos elementos contrafactuais e dos polos temáticos de Ficção Científica, conforme caracterizados por Piassi (2007). Com isso, foram explorados os potenciais didáticos presentes nas HQs, bem como proposta uma Sequência Didática que tem como tema "Ecossistemas e Relações ecológicas" e foi organizada nos Três Momentos Pedagógicos, sendo voltada para o Ensino Fundamental. Conteúdos específicos (como relações intra e interespecíficas), além de tecnologias e temas sociais relacionados à biodiversidade e degradação ambiental foram abordados.
\end{abstract}

Palavras-chave: Ficção Científica. Histórias em Quadrinhos. Educação Científica. Sequência Didática. Recurso Didático.

\begin{abstract}
Comics (comic books) are an efficient resource as an incentive to reading, in addition to being an important aid in the teaching of Science, showing they capable of promoting interdisciplinarity between curricular content and students' imaginary extrapolation. Based on this assumption, this article reports a research in which a documental analysis of the X-Men's "X Dynasty" and "X Powers" miniseries was carried out, through the identification of the Science Fiction counterfactual elements and thematic poles, as characterized by Piassi (2007). Thus, the didactic potentials present in the comics were explored and a didactic sequence was proposed. This theme is "Ecosystems and Ecological Relations" and was organized in the Three Pedagogical Moments, being geared towards elementary school. Specific contents (such as intra and interspecific relationships), as well as technologies and social issues related to biodiversity and environmental degradation were addressed.
\end{abstract}

\footnotetext{
* Licenciado em Ciências Biológicas pela Universidade do Estado do Rio de Janeiro (UERJ). Mestrando do Programa de Pós-Graduação em Ensino de Ciências, Ambiente e Sociedade (PPGEAS-UERJ), São Gonçalo, RJ, Brasil. Endereço para correspondência: Rua Dr. Francisco Portela, 1470, Patronato, São Gonçalo, RJ, Brasil, CEP: 24435-005. E-mail: lu.lucianojunior@gmail.com.

** Doutora em Educação Científica e Tecnológica pela Universidade Federal de Santa Catarina (UFSC). Professora Associada da Universidade do Estado do Rio de Janeiro, Faculdade de Formação de Professores (UERJ-FFP), São Gonçalo, RJ, Brasil. Endereço para correspondência: Rua Dr. Francisco Portela, 1470, Patronato, São Gonçalo, RJ, Brasil, CEP: 24435-005. E-mail: tatigalieta @ gmail.com.
} 
Keywords: Science Fiction. Comics. Science Education. Sequence Teaching. Teaching Resource.

\section{RESUMEN}

Los cómics (historietas) son un recurso eficaz como incentivo a la lectura, además de ser una importante ayuda en la enseñanza de las Ciencias, mostrándose capaces de promover la interdisciplinariedad entre los contenidos curriculares y la extrapolación imaginaria de los estudiantes. Con base en este supuesto, este artículo reporta una investigación en la que se realizó un análisis documental de las miniseries "Dinastía X" y "Potencias de X" de los X-Men, a través de la identificación de los elementos contrafactuales y polos temáticos de la Ciencia Ficción, como lo caracteriza Piassi (2007). Así, se exploraron las potencialidades didácticas presentes en los cómics y se propuso una secuencia didáctica. Este tema es "Ecosistemas y Relaciones Ecológicas" y fue organizado en los Tres Momentos Pedagógicos, dirigido a Educación Primaria. Se abordaron contenidos específicos (como relaciones intra e interespecíficas), así como tecnologías y temas sociales relacionados con la biodiversidad y la degradación ambiental.

Palabras clave: Ciencia Ficción. Cómics. Educación Científica. Secuencia Didáctica. Recurso Didáctico.

\section{A FICÇÃO CIENTÍFICA E SEU POTENCIAL DIDÁTICO}

Obras de Ficção Científica, geralmente, não são produzidas com objetivos didáticos, sendo descritas como manifestações artísticas. Com isso, o uso delas em sala de aula se justificam na medida em que se torna possível explorar elementos que outros recursos didáticos não podem proporcionar. Segundo Piassi (2012, p. 210):

(...) o uso da Ficção Científica é particularmente interessante quando entendemos o conteúdo escolar a partir de uma perspectiva que considera não apenas os aspectos conceituais e fenomenológicos das ciências, mas também a abordagem de temas ligados ao fazer científico e às relações que a ciência estabelece com outros âmbitos da cultura humana.

A Ficção Científica, para Piassi e Pietrocola (2009), é um dos gêneros mais ricos para trabalhar a temática científica em sala de aula, possuindo diversas abordagens possíveis e conceitos diversificados. A partir desses autores, nós a entendemos não como um gênero que possui qualquer relação com a ciência, mas sim que emprega uma racionalidade do tipo científica para produzir conjecturas sobre a realidade, visto que, por meio da derivação ou variação, sua narrativa é pautada pela conjectura dentro dos limites da racionalidade lógicocausal. Dessa forma, é orientada para a exploração dos efeitos humanos decorrentes do estabelecimento de um novum, que é disparador de conjecturas. Daí decorre seu efeito literário. 
A Ficção Científica extrapola fatos a partir da retórica lógico-casual e racional da ciência. Nesse aspecto, a “especulação contrafactual "' de Eco (1989) apud Piassi e Pietrocola (2009) engloba elementos que não estão presentes no mundo real, mas que na Ficção Científica é um fato que não precisa ser explicado dentro daquele contexto. De acordo com os autores, “(...) a construção do contrafactual acontece, portanto, a partir de um fato conhecido cientificamente, contrapondo-se a ele por meio da apropriação do discurso científico", ou pelo uso de expressões (terminologias, léxicos e imagens) ou de conteúdos (conceitos, relações e processos de raciocínio) (PIASSI e PIETROCOLA, 2009, p. 529). Ressalta-se que a identificação dos elementos contrafactuais em uma obra auxilia sua própria caracterização como Ficção Científica (Piassi, 2007).

Entre os vários tipos de textos que compõem o gênero Ficção Científica (livros, filmes, séries de TV, por exemplo), focamos nas Histórias em Quadrinhos (HQs), que, segundo Siani (2003), são uma expressão cultural da sociedade moderna, apresentando-se numa diversidade de tipos, traços, personagens, tramas e contextos, muitas vezes difíceis de rotular e classificar. Para Santos e Ganzarolli (2011), as HQs são um recurso muito eficiente como incentivo à leitura, além de um importante auxiliar no ensino, contribuindo para a formação de leitores mais competentes, inclusive podendo ser utilizadas de diversas maneiras no ambiente escolar, auxiliando no ensino em diversas disciplinas e atividades. Em específico, voltamos nossa atenção a um tipo de HQ, as histórias sobre super-heróis. De acordo com Silva (2019, p. 18), estas histórias “constituem um gênero a parte, que se constrói através da união de diversos gêneros e/ou subgêneros literários. Isso quer dizer que, assim como o gênero de Ficção Científica não é homogêneo, as histórias de super-heróis também não são”.

O autor supracitado, em busca de compreender como a Ficção Científica tem sido considerada na área de Educação em Ciências, realizou um levantamento bibliográfico nas atas eletrônicas do Encontro Nacional de Pesquisa em Educação em Ciências (ENPEC), mais precisamente da VIII (2011) a XI (2017) edição (SILVA, 2019). Os trabalhos localizados foram classificados de acordo com o tipo de arte: $6^{\mathrm{a}}$ arte (livros), $7^{\mathrm{a}}$ (cinema) e $9^{\mathrm{a}}$ arte (quadrinhos). A fim de atualizar os dados de Silva (2019), fizemos uma busca nas atas do XII ENPEC (2019) e percebemos que a soma de ambos os levantamentos resultou em 15

\footnotetext{
1 Especulação é a ação de pensamento e de questionamento de possibilidades. Contrafactual remete à contraposição em relação aos fatos, a negação de um fato. O termo "especulação contrafactual" segundo os autores se trata disso, especulações de possibilidades sem levar em consideração fatos do nosso mundo real.
} 
trabalhos sobre ficção científica nas cinco edições do ENPEC investigadas, dos quais somente dois abordavam HQs.

O trabalho de Nascimento Jr. e Piassi (2011) fez uma investigação sobre o potencial didático que as histórias em quadrinhos de Ficção Científica têm para uso no ensino de Física de nível médio. Por meio de uma análise semiótica, foi possível observar que a leitura pode estimular a reflexão sobre aspectos conceituais e epistemológicos da Física contemporânea, com uma aproximação transdisciplinar. Já Albuquerque e Ramos (2015) apresentam análises preliminares de roteiros de HQs produzidos por estudantes do Ensino Fundamental durante uma atividade prática diferenciada, envolvendo o tema radiação. Notou-se que a maioria dos estudantes conseguiu diferenciar ciência de ficção, mas, ao redigirem as histórias de ficção, esta tomou o lugar da ciência.

A partir da identificação desta lacuna de pesquisas sobre os usos da Ficção Científica em HQs, foi elaborada uma pesquisa cujo objetivo consistiu em analisar uma história em quadrinho do gênero de super-heróis, mais precisamente a revista dos X-Men, identificando os elementos de Ficção Científica (PIASSI, 2007) para, a partir disso, extrair os potenciais didáticos para o ensino de Ciências e Biologia (SOUSA JUNIOR, 2020). Neste artigo, é apresentada uma parte dos resultados desse estudo.

\section{HISTÓRIAS EM QUADRINHOS DE SUPER-HERÓIS MUTANTES: OS X-MEN}

O gênero de quadrinhos intitulado como super-heróis foi inaugurado por fins da década de 1930, dando início às atualmente chamadas "Eras" dos quadrinhos (KRAKHECKE, 2009). As histórias de super-heróis ganharam força com a criação de "Superman". O herói já era publicado desde junho de 1938 nas páginas da revista "Action Comics", porém, em julho de 1939, passa a ter destaque com a criação da revista "Superman". Aqui, assim como nas décadas subsequentes, o contexto social da época foi de extrema importância para a construção das histórias e personagens.

Neste século ocorreu uma guinada nas adaptações de personagens dos quadrinhos para o cinema, prática que passou a ser muito comum desde então. Com o advento das modernas tecnologias de computação gráfica, foram possíveis de reproduzir, com algum grau de realismo, as façanhas dos super-heróis em filmes (ROSA, 2014). Em 2000, os super-heróis mutantes protagonizaram sua adaptação para os cinemas, em "X-Men - O Filme", retomando certa parte da atenção e apreço do público, o que acabou incentivando outros estúdios a 
apostarem em novas adaptações baseadas em outros títulos e grupos originados das HQs. A filmografia baseada em HQs promoveu uma nova onda de popularização do gênero.

As HQs estreladas por personagens que sofreram mutações genéticas, os $X$-Men, são o objeto de estudo desta pesquisa. Nas histórias desses super-heróis, os mutantes são humanos que expressam o "gene-X". Mutações aleatórias no seu código genético desbloqueiam esse gene dormente e a sua expressão produz poderes manifestados por determinadas proteínas. Nos $X$-Men, o gene $\mathrm{X}$ codifica uma proteína que, por sua vez, produz sinais bioquímicos para todo o corpo, induzindo mutações em outros genes. Ser um mutante, portanto, é o resultado de uma cascata química radical, no qual as mutações genéticas não são as mesmas em todos eles. Isso confere uma série de poderes e habilidades extraordinárias aos personagens vistos ao longo das histórias criadas por Stan Lee e Jack Kirby, tal como o professor Charles Xavier, que é um poderoso telepata capaz de ler e controlar mentes ao redor do planeta.

Consideramos 12 revistas ou edições, divididas em duas partes (as minisséries): "Dinastia X", do volume 1 ao 6, e "Potências de X", do volume 1 ao 6, publicadas entre os meses de julho e novembro de 2019 (MARVEL COMICS, 2020a; 2020b) e escritas por Jonathan Hickman. A ordem de leitura das edições ocorre de maneira sucessiva e intercalada por meio dos títulos, por exemplo: após Dinastia X \#1 vem Potências de X \#1, após Dinastia $X$ \#2 vem Potências de X \#2 e assim sucessivamente, totalizando as 12 revistas, salientando que cada uma delas é composta por cerca de 35 páginas, levando em consideração os índices e anexos.

A protagonista das minisséries é Charles Xavier, o Professor X. Ele cria uma nação mutante, habitada na Ilha Krakoa, um país mutante mundialmente reconhecido pelas entidades governamentais, com suas próprias leis econômicas e políticas, códigos morais e sociais. No quadro 1, apresentamos uma sinopse das 12 edições.

\begin{tabular}{|c|l|}
\hline No da edição & \multicolumn{1}{c|}{ Sinopse } \\
\hline Dinastia X \#1 & $\begin{array}{l}\text { Charles Xavier quer compartilhar com o mundo as descobertas que fez em sua } \\
\text { ilha de Krakoa e tudo que quer em troca é ser reconhecido como uma nação } \\
\text { autônoma. }\end{array}$ \\
\hline Potências de X\#1 & $\begin{array}{l}\text { Passado, presente e futuro se encontram quando somos apresentados à nova } \\
\text { realidade dos X-Men no universo Marvel. }\end{array}$ \\
\hline Dinastia X \#2 & $\begin{array}{l}\text { São apresentadas as muitas vidas de Moira (personagem) e como ela interferiu } \\
\text { no universo mutante. }\end{array}$ \\
\hline Potências de X\#2 & $\begin{array}{l}\text { O plano da Orquídea (organização mundial dedicada a uma resposta a um } \\
\text { possível cenário de apocalipse; já foi responsável por reduzir a população } \\
\text { mutante) começa a ser revelado graças ao drive roubado por Mística } \\
\text { (personagem). A sociedade Tecnárquia do futuro começa a ser explicada. }\end{array}$ \\
\hline
\end{tabular}




\begin{tabular}{|c|c|}
\hline Potências de X \#3 & $\begin{array}{l}\text { Em uma das vidas de Moira, a mais de } 100 \text { anos no futuro, o mutante conhecido } \\
\text { como Apocalipse e seus aliados fazem um ataque suicida definitivo contra as } \\
\text { forças de Nimrod, uma Inteligência Artificial que caça e extermina humanos e } \\
\text { mutantes. }\end{array}$ \\
\hline Dinastia X \#3 & $\begin{array}{l}\text { O super-herói e mutante Ciclope lidera uma equipe de elite mutante com Jean } \\
\text { Grey, Wolverine, Arcanjo entre outros heróis para invadir e destruir a Molde } \\
\text { Mãe (uma instalação que cria armas de caça e extermínio mutante) na órbita do } \\
\text { Sol antes que ela fique operacional. }\end{array}$ \\
\hline Dinastia X \#4 & $\begin{array}{l}\text { A missão de Ciclope e sua equipe toma proporções muito arriscadas contra o } \\
\text { Molde Mãe e passa a ser considerada uma missão suicida. }\end{array}$ \\
\hline Potências de X \#4 & $\begin{array}{l}\text { Mostra Xavier e Magneto no passado (alguns meses antes de a história se passar } \\
\text { em Krakoa), formando novas e letais alianças para garantir a sobrevida mutante } \\
\text { no presente e futuro. Mais sobre a ilha de Krakoa é apresentado. }\end{array}$ \\
\hline Dinastia X \#5 & $\begin{array}{l}\text { Os } X \text {-Men morreram no espaço ao impedir a Orquídea. Agora, Krakoa precisa } \\
\text { sobreviver e ser reconhecida como nação. Xavier revela um grande trunfo da } \\
\text { nação mutante. }\end{array}$ \\
\hline Potências de X \#5 & $\begin{array}{l}\text { Xavier tem um plano para os mutantes e, para isso. ele vai atrás de Forge } \\
\text { (personagem provido de super. inteligência) para melhorar a tecnologia do } \\
\text { Cérebro (um dispositivo que amplifica as habilidades de Xavier), tornando-o } \\
\text { capaz de fazer os backups de diversas mentes e será usado no processo de } \\
\text { ressurreição. }\end{array}$ \\
\hline Dinastia X \#6 & $\begin{array}{l}\text { A primeira reunião do conselho de Krakoa é feita e ganha um espaço na mesa da } \\
\text { ONU, apesar de ainda enfrentar rejeições. As primeiras leis mutantes são criadas. }\end{array}$ \\
\hline Potências de X \#6 & $\begin{array}{l}\text { O Conselho Silencioso (o corpo governante de doze membros encarregados de } \\
\text { criar e fazer cumprir as leis do estado-nação sobre Krakoa) foi formado. Chegou } \\
\text { a hora do Alvorecer do X. }\end{array}$ \\
\hline
\end{tabular}

Quadro 1. Sinopse das 12 edições das minisséries "Dinastia X" e "Potências de X".

Fonte. SOUSA JUNIOR, 2020.

A minissérie permite abordar muitos assuntos que podem ser tratados não só em aulas de Ciências, como também nas de Geografia, Química, Sociologia e Filosofia, tais como: a diversidade, preservação do meio ambiente, evolução, ética e cidadania. No caso específico da disciplina Ciências, ressaltamos a relação dos mutantes com a ilha de Krakoa, com os seres estando mutuamente inseridos na natureza, sendo pertencentes a ela. Esse ponto, em particular, pode contribuir para a desconstrução de uma visão utilitarista e dicotômica entre homem e ambiente. Além disso, as relações entre seres da mesma espécie ou de espécies distintas permitem a inserção de conteúdos ecológicos a partir de situações vivenciadas pelas personagens das HQs.

\section{METODOLOGIA}

A pesquisa caracteriza-se como qualitativa e com análise documental a partir de categorias empíricas estabelecidas com base na literatura. Para Flick (2009), a pesquisa 
qualitativa contém várias características específicas, utilizando o texto como material empírico ao invés de números. Consiste, portanto, em uma atividade em que o observador produz interpretações sobre materiais que tornam o mundo visível.

Mendonça e Correia (2008) descrevem algumas das técnicas de coleta de dados das quais a pesquisa qualitativa se utiliza, denominadas: observação direta ou indireta, entrevista, questionário, análise de documentos e análise de artefatos culturais. A fonte de dados desta pesquisa consiste em documentos, mais precisamente, sob as HQs aqui selecionadas (as minisséries "Dinastia X" e "Potências de X"). Sendo uma técnica muito comum e decisiva para a pesquisa em Ciências Sociais e Humanas, a Análise Documental é indispensável porque a maior parte das fontes escritas é quase sempre a base do trabalho de investigação. É realizada a partir de documentos, contemporâneos ou retrospectivos, considerados cientificamente autênticos (ABREU, 2008).

Primeiramente, realizou-se a leitura das revistas para uma breve orientação sobre a narrativa e os temas tratados. Com isso, deu-se início a uma análise documental da minissérie, a fim de identificar os tópicos que poderiam ser usados nas aulas de Ciências. Essa análise buscou também a identificação dos elementos contrafactuais para que a estruturação dos polos temáticos (Piassi, 2007) presentes nas revistas fosse possível.

Os elementos são os seres, que desempenham um papel personificado e ativo; os objetos, que são inanimados e não possuem autonomia relativa, o ambiente, no qual se dão as ações e as instituições, que elementos com características mais abstratas, como por exemplo, governos, religiões, idiomas e ciência (PIASSI, 2007). Por outro lado, os elementos não se definem apenas por sua descrição estética, mas principalmente pelos predicados a eles associados, inclusive, são esses recursos que definem o que "pode ou não pode" acontecer no decurso da ação, provendo o desencadeamento necessário para o desenvolvimento lógico da história. Os seres são definidos em função de determinados poderes que eles dispõem, que os contrapõe aos poderes conhecidos dos "seres normais de referência" que, na maioria dos casos, são os humanos.

O ambiente também é definido dialeticamente pelos fenômenos que são capazes de gerar junto das interações dos objetos e seres que encontram existência nesse ambiente. Destes objetos, observamos a demonstração de determinadas propriedades incomuns das quais podemos notar sua contrafactualidade em relação aos "objetos normais de referência" de nosso mundo (PIASSI, 2007, p. 188). Por fim, temos as instituições que são descritas pelo autor como elementos abstratos dados pela criação conceitual (governos, idiomas, 
ciências), destacando que todos esses objetos podem ser de criação contrafactual, mas o que definirá dialeticamente tais elementos são as leis. Há dois tipos de leis, segundo o autor: as leis prescritivas (de caráter normativo) que são leis, regras ou costumes impostos aos seres que podem e serão desobedecidas dando andamento à ação da história, bem como as leis descritivas (de caráter cientifico), que delimitam as possibilidades de ação naquele determinado ambiente (PIASSI, 2007, p. 189).

Além das categorias "elementos" e "predicados", usamos os "polos temáticos", conforme definido por Piassi (2007) na análise das HQs. O autor classifica o primeiro polo em uma associação à ciência e tecnologia ao "o conforto", “o bem-estar", superar e vencer as dificuldades, dominando a natureza e suas ameaças, chamando esse polo de materialeconômico. Ressalta-se que essa ligação pode ser vista de forma positiva (eufórica) ou negativa (disfórica), como o autor denomina: polo eufórico, em que em um momento temos a associação positiva da ciência e tecnologia, sendo vistas como provedoras de soluções, avanços e melhorias da qualidade de vida, e o oposto chama-se polo disfórico, vistas de formas negativas, ligadas a causas da degradação, destruição e da piora das condições gerais de vida da humanidade. Já o outro polo temático é denominado polo existencial-filosófico, o qual trata a ciência como uma busca de conhecimento puro, de compreensão do universo e da busca de respostas existenciais para as buscas mais profundas da humanidade. Aqui, também teremos uma associação negativa, considerando a ciência como incapaz de fornecer as respostas importantes para a humanidade, o que configura esse papel a outras formas de conhecimento. Já no caso positivo, a ciência é vista como um caminho privilegiado para a obtenção de respostas acerca do universo, da natureza humana e de questões gerais do gênero.

Os resultados derivados da análise dessas categorias (polos) possibilitaram a elaboração de quadros que posteriormente serviram como um dos recursos propostos na Sequência Didática que foi elaborada tendo como base a dinâmica dos Três Momentos Pedagógicos idealizada por Delizoicov, Angotti e Pernambuco (2002). São eles:

- Problematização Inicial (PI): A problematização inicial (PI) apresenta como função não somente iniciar a discussão de um dado conteúdo, e sim expor aos alunos situações reais que eles conhecem e vivenciam, por meio de uma situação-problema, possíveis de estudar um conhecimento científico de interesse. A ideia é identificar as concepções prévias deles sobre o tema e fazer com que eles sintam necessidade de novos conhecimentos para resolver a problemática em questão. 
- Organização do Conhecimento (OC): Foca no estudo dos conteúdos necessários para a resolução da situação-problema inicial. Esse é o momento de se estabelecerem relações, desenvolverem definições e conceitos, no sentido de apresentar aos alunos outras explicações para a situação problematizada, de modo que eles comparem esse conhecimento com o seu e proponham uma nova explicação para a situação investigada.

- Aplicação do Conhecimento (AC): Os alunos são instigados a empregar seus novos conceitos apreendidos no segundo momento (OC), estabelecendo relações para resolver a problemática inicial. Por fim, é o momento também de extrapolar e explorar novos contextos, os quais não possuem relação direta com a situação-problema exposta na problematização inicial, mas necessitam dos mesmos conceitos para serem resolvidas (GIACOMINI, 2015).

Tal abordagem metodológica de ensino foi inspirada na perspectiva freireana constituída em investigações temáticas e na dialogicidade, composta por três etapas: problematização inicial, organização do conhecimento e aplicação do conhecimento (DELIZOICOV, ANGOTTI e PERNAMBUCO, 2002).

A Sequência Didática foi elaborada com base nos passos básicos delimitados por Oliveira (2013), a saber: a) escolha do tema a ser trabalhado; b) questionamentos para problematização do assunto a ser trabalhado; c) planejamento dos conteúdos e objetivos a serem atingidos no processo de ensino-aprendizagem; d) delimitação da sequência de atividades, levando-se em consideração a formação de grupos, material didático, cronograma, integração entre cada atividade e etapas e e) avaliação dos resultados.

\section{ANÁLISES E RESULTADOS}

No Quadro 2, elencamos os elementos contrafactuais presentes nas minisséries analisadas e, em seguida, apresentamos a classificação desses elementos junto a seus predicados.

\begin{tabular}{|l|l|}
\hline \multicolumn{1}{|c|}{ Elementos } & \multicolumn{1}{c|}{ Descrição } \\
\hline $\begin{array}{l}\text { Os super-heróis } \\
\text { mutantes }\end{array}$ & $\begin{array}{l}\text { Os personagens das revistas são humanos que passaram por um processo de mutação } \\
\text { pelo despertar do gene x. Essa mutação concedeu habilidades extraordinárias a essas } \\
\text { pessoas e o surgimento de uma nova espécie intitulada Homo superior, que se difere } \\
\text { dos humanos conhecidos por Homo sapiens. }\end{array}$ \\
\hline $\begin{array}{l}\text { Uma Ilha Viva e } \\
\text { Mutante }\end{array}$ & $\begin{array}{l}\text { A Ilha Krakoa é um ecossistema vivo e mutante, se identifica como fauna. Possui } \\
\text { controle sobre seu espaço e suas próprias condições de convivência com os mutantes. }\end{array}$ \\
\hline $\begin{array}{l}\text { A flora única da } \\
\text { ilha }\end{array}$ & $\begin{array}{l}\text { A flora única da Ilha Mutante Krakoa concede inúmeras vantagens ao povo humano, } \\
\text { com suas flores com potencial medicinal para a cura de inúmeras doenças ao povo } \\
\text { mutante com seus portais de deslocamento no espaço, que permitem a locomoção de }\end{array}$ \\
\hline \hline
\end{tabular}




\begin{tabular}{|c|c|}
\hline & um ponto a outro. \\
\hline $\begin{array}{l}\text { A tecnologia } \\
\text { avançada usada } \\
\text { pelos heróis. }\end{array}$ & $\begin{array}{l}\text { Durante as revistas, vemos que a tecnologia usada pelos protagonistas das revistas é } \\
\text { atemporal a sua realidade. Naves espaciais que permitem uma viagem à órbita do sol e } \\
\text { o mecanismo de amplificação de poderes (Cérebro) do professor Xavier são exemplos } \\
\text { disso. }\end{array}$ \\
\hline $\begin{array}{l}\text { O surgimento de } \\
\text { um novo idioma e } \\
\text { cultura. }\end{array}$ & $\begin{array}{l}\text { O idioma Krakoano é específico da nação mutante, criado pelo mutante Cifra e pela } \\
\text { própria ilha Krakoa, mostrando que não se pode criar uma cultura sem um idioma. }\end{array}$ \\
\hline $\begin{array}{l}\text { As diversas } \\
\text { realidades da } \\
\text { revista }\end{array}$ & $\begin{array}{l}\text { As habilidades de Moira permitem que ela ressuscite sempre que morre, mantendo as } \\
\text { memórias das vidas passadas e, com isso, Moira viveu diversas realidades em muitas } \\
\text { vidas. Conheceu vários rumos que as histórias da humanidade e mutante tiveram. }\end{array}$ \\
\hline $\begin{array}{l}\text { O processo de } \\
\text { ressurreição }\end{array}$ & $\begin{array}{l}\text { Um procedimento exclusivo do povo mutante, por meio das habilidades do Professor } \\
\text { Xavier, que possui a capacidade de criar um banco de dados das mentes dos mutantes } \\
\text { presentes na ilha (um backup), combinados ao acervo de material genético reunido ao } \\
\text { longo dos anos pelo mutante conhecido como Sr. Sinistro e o dom de cinco mutantes } \\
\text { específicos junto do bioma único da ilha, se torna possível trazer mutantes que } \\
\text { faleceram de volta à vida. }\end{array}$ \\
\hline $\begin{array}{l}\text { O extermínio de } \\
\text { uma espécie }\end{array}$ & $\begin{array}{l}\text { É possível perceber que em diversas realidades algumas espécies são extintas, em sua } \\
\text { maioria a dos mutantes, o que gera impactos catastróficos no equilíbrio do planeta } \\
\text { Terra e futuros distópicos. }\end{array}$ \\
\hline $\begin{array}{l}\text { A criação de uma } \\
\text { nação Mutante }\end{array}$ & $\begin{array}{l}\text { O cerne da história gira na tentativa do Professo X abrigar e criar uma nação mutante } \\
\text { na Ilha Krakoa, o que mostra diversos pontos políticos, econômicos, diplomáticos e } \\
\text { críticos sobre como ocorre esse processo de criação. }\end{array}$ \\
\hline
\end{tabular}

Quadro 2. Elementos contrafactuais identificados nas HQs analisadas.

Fonte. SOUSA JUNIOR, 2020.

Os super-heróis mutantes são os protagonistas da minissérie, junto com os humanos do restante do mundo, e as máquinas também recebem um papel importante na trama, afinal, são um dos antagonistas do enredo que desempenham um papel ativo e personificado ao longo das edições, logo, os denominaremos na categoria dos seres. Os poderes observados nas edições são feitos de maneira bem nítida e visível, com a exibição de diversas habilidades extraordinárias por parte dos mutantes. Vemos a dimensão desses poderes alcançar os dois extremos, tais como: ler pensamentos, até mesmo a manipulação e alteração da realidade e, por outro lado, temos poderes mais simples que, por mais fantasiosos que sejam, conseguem ter uma dimensão mais real da compreensão humana, tais como a capacidade de se comunicar com qualquer idioma falado ou escrito, a capacidade de voar e a super velocidade. Coisas que os humanos, que são os "seres de referência", não podem fazer. Em contrapartida, os humanos criam as máquinas e armas para caçar e exterminar a espécie mutante.

O ambiente da obra se passa pela maior parte da história no Planeta Terra, mais precisamente na Ilha Viva Mutante Krakoa. É nesse ambiente que podemos observar diversos fenômenos como os portais de translocação de matéria no espaço e o de ressureição mutante. 
Podemos destacar que os principais objetos da obra são as tecnologias vistas e usadas pelos grupos mutantes e as flores de Krakoa que possuem um efeito medicinal exclusivo aos humanos. Tais objetos são, de certa forma, inanimados na narrativa. Porém, eles possuem propriedades que os tornam úteis para a trama, pois enquanto o uso da tecnologia permite a exploração do espaço e a chegada do grupo mutante à órbita do sol, as flores agem como potenciais incentivadoras da economia mutante e como moeda de troca. Por fim, as instituições presentes na trama, que se dividem por três aspectos: a criação da nação Mutante, em paralelo com o surgimento de um novo idioma e cultura. Temos diversos saltos temporais na narrativa da história que são demonstradas pelas realidades das revistas, as quais mostram passado, presente e futuro e cada uma com uma visão governamental, religiosa e científica alternada, dependendo da época. Como as próprias revistas não se aprofundam sobre essas realidades vividas pela deuteragonista Moira, aqui não vamos entrar em mais detalhes sobre como as instituições se dispõem através dos tempos presentes nas revistas. Contudo, podemos destacar um aspecto peculiar acerca das instituições, suas leis.

Na trama, vemos todo o esforço do professor Xavier ao tentar criar a nação mutante e isso dispõe de diversas leis: a diplomacia mutante, as leis de proteção e julgamento mutante, assim como um código de ética dos mutantes acerca de seus procedimentos, como o processo de ressureição que desafia as leis científicas do nosso mundo real, mas que, no mundo fictício, é regido por uma série de leis prescritivas e descritivas pelos mutantes. Com isso, observamos como os elementos e seus predicados se dispõem nas minisséries (Quadro 3).

\begin{tabular}{|c|c|}
\hline Elementos & Predicados \\
\hline $\begin{array}{l}\text { Seres }{ }^{1} \text { : Os super- } \\
\text { heróis mutantes (Homo } \\
\text { superior) } \\
\text { Seres }{ }^{2} \text { : As máquinas } \\
\text { criadas pelos humanos }\end{array}$ & $\begin{array}{l}\text { Poderes 1: Habilidades excepcionais geradas pela ativação do gene mutante X (tais } \\
\text { como a capacidade de voar, ler mentes, disparar rajadas de energia etc.). } \\
\text { Poderes }^{2} \text { : Os próprios seres humanos. São responsáveis por criar máquinas de } \\
\text { caça e extermínio mutante que em uma das realidades vividas por Moira foi } \\
\text { responsável pela extinção das espécies mutante e humana e se tornou dominante. }\end{array}$ \\
\hline $\begin{array}{l}\text { Objetos }{ }^{1} \text { : Naves } \\
\text { aeroespaciais e } \\
\text { uniformes } \\
\text { Objeto }^{2} \text { : Cérebro } \\
\text { Objetos }^{3} \text { : flores de } \\
\text { Krakoa }\end{array}$ & $\begin{array}{l}\text { Propriedades }{ }^{1} \text { : As tecnologias permitem a exploração do espaço, naves que } \\
\text { atingem a velocidades da luz por exemplo, os uniformes protegem os super-heróis } \\
\text { em ambiente inóspito. } \\
\text { Propriedades }^{2} \text { : Dispositivo tecnológico capaz de ampliar as habilidades de Xavier } \\
\text { tem papel importantíssimo no processo de ressurreição. } \\
\text { Propriedade }^{3} \text { : as flores possuem propriedades medicinais para os humanos. }\end{array}$ \\
\hline $\begin{array}{l}\text { Ambiente }{ }^{\mathbf{1}} \text { : Ilha } \\
\text { Mutante Krakoa } \\
\text { Ambiente }^{2} \text { : Planeta } \\
\text { Terra }\end{array}$ & $\begin{array}{l}\text { Fenômenos': Portais de translocação de matéria no espaço e único ambiente } \\
\text { possível para a realização do processo de ressureição mutante. } \\
\text { Fenômenos }{ }^{2} \text { : Em uma das realidades vividas por Moira, vemos que a espécie } \\
\text { mutante foi extinta do Planeta Terra, o que gerou profundas marcas no equilíbrio do } \\
\text { planeta, afetando diretamente todas as outras espécies, inclusive a humana. }\end{array}$ \\
\hline
\end{tabular}




\begin{tabular}{|l|l|}
\hline $\begin{array}{l}\text { Instituição }{ }^{1}: \text { Nação } \\
\text { Mutante }\end{array}$ & $\begin{array}{l}\text { Leis }^{1} \text { : Através da criação da nova nação, é mostrado o processo de surgimento do } \\
\text { Conselho Silencioso (forma de governo composta por 12 membros mutantes, } \\
\text { responsáveis por criar as primeiras leis de proteção e julgamento mutante, código de } \\
\text { Instituição }{ }^{2}: \text { Novo } \\
\text { idioma e cultura }\end{array}$ \\
$\begin{array}{l}\text { ética mutante). } \\
\text { Leis }{ }^{2}: \text { Segundo Magneto, é impossível a criação de uma nova cultura sem um } \\
\text { idioma próprio, o Krakoano. }\end{array}$ \\
\hline
\end{tabular}

Quadro 3. Elementos e predicados das HQs analisadas.

Fonte. SOUSA JUNIOR, 2020.

A partir da identificação dos elementos contrafactuais, foram estruturados os polos temáticos (Figura 1), tendo como auxiliador as três perguntas propostas por Piassi (2007):

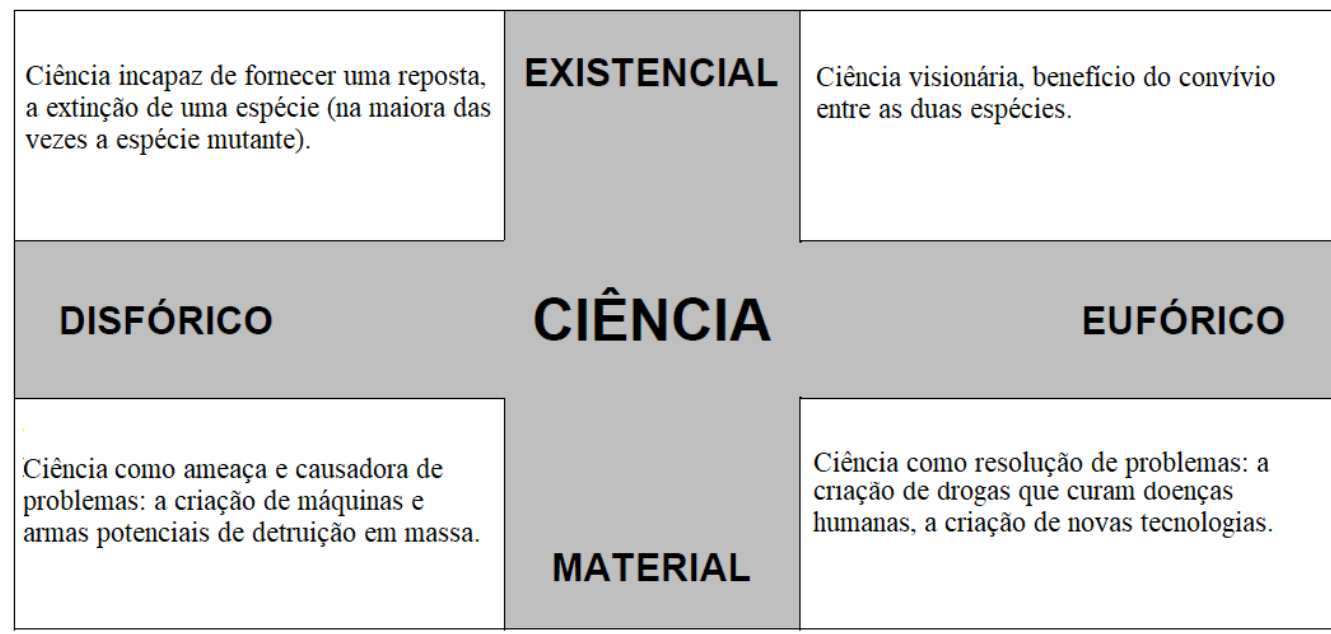

Figura 1. Polos temáticos identificados nas HQs analisadas.

Fonte: SOUSA JUNIOR, 2020.

1. Podemos identificar na obra a expressão de um desejo? Sim, o desejo de uma convivência harmônica entre duas espécies, a espécie humana (Homo sapiens) e a espécie mutante (Homo superior), idealizado por Charles Xavier.

2. Tal desejo é satisfeito? Em caso afirmativo, como? Em caso negativo, por quê? Para esta pergunta, temos as duas respostas. Respectivamente, no evento narrado, podemos ver que, após enormes sacrifícios e tentativas, o sonho de Xavier se concretiza, já que ele faz com que Krakoa seja reconhecida como a primeira nação autônoma mutante do mundo. Ao mesmo tempo, vemos que em nove ocasiões diferentes (que são as vidas passadas de Moira) esse desejo não se torna realidade, em todos os casos sendo frustrado pelos humanos ou, em futuros diferentes, por criações humanas que sobrepujaram ambas as espécies.

3. Quais interpretações podem ser associadas a este desejo? O desejo de Xavier vai de encontro à unidade temática "Vida e Evolução" (RIO DE JANEIRO, 2019), em que temos questões relacionadas aos seres vivos, suas características e necessidades. Notamos a vida 
como fenômeno também social, a compreensão dos processos evolutivos e consequente diversidade de seres vivos no planeta. Todo processo de desenvolvimento da nova nação ocorre com a autorização da própria Ilha Krakoa, o que levanta os assuntos acerca dos ecossistemas e as relações entre os seres vivos, destacando o potencial antrópico de transformação do ambiente, fomentando as posturas éticas e morais para tomada de decisões.

Ao contrapor o polo material/econômico disfórico e eufórico, podemos discutir os efeitos negativos do avanço científico e tecnológico voltados a uma visão do uso da ciência como ameaça, como arma de controle de uma espécie que está sendo subjugada por outra (nesse caso, os mutantes) que, em contrapartida, poderia ser usada para prover a solução de um determinado problema, como a criação de drogas que curam doenças e outras tecnologias que beneficiem ambas as espécies. Isso nos permite uma breve discussão sobre a natureza humana e mutante das revistas e sua relação com o meio. Essa relação pode orientar debates acerca de um pensamento muito presente nas revistas, que é o convívio mútuo entre as espécies. Vemos, por parte dos humanos, que há um receio de que a espécie mutante um dia seja a dominante, então, diversos meios de frear esse crescimento populacional da espécie mutante são criados. Somos apresentados a uma série de fatores que desencadeiam um desfecho ruim para ambas as espécies, tais como desequilíbrios ecológicos, mudanças climáticas, rebelião e retaliação das máquinas e suas inteligências artificiais, todas essas ameaças em escala global, e esses efeitos negativos, por sua vez, estão intimamente ligados com o meio em que vivemos.

Se formos analisar o polo filosófico/existencial disfórico e eufórico, percebemos isso, visto que em um momento a Ciência é incapaz de fornecer uma resposta, culminando sempre na extinção de alguma espécie (na maioria das vezes a mutante), em contrapartida, temos uma realidade em que uma Ciência visionária caminha para uma possível convivência benéfica entre as espécies. Ainda é possível a discussão sobre a Natureza da Ciência, abordando a relação entre o que a Ciência faz e quais as consequências desses atos para a Sociedade.

Outra questão que permeia é dada na contraposição do polo material-econômico eufórico com o existencial-filosófico eufórico. Vemos nas revistas que a Ciência e a tecnologia mutantes são benéficas a ponto de permitir o processo de ressurreição de uma espécie. Seria esse um fator exclusivamente positivo? Afinal, se neste mundo fictício os mutantes ainda não possuem leis, como abordaríamos a bioética por trás desse processo? Essa discussão possivelmente despertaria aspectos tanto negativos, quanto positivos para a sociedade. Nas revistas, é possível notar que a maioria dos cientistas e entidades 
governamentais sabe da existência dos mutantes (Homo superior), ainda que existam cientistas que tratem de forma cética essa existência. Há o medo de que essa nova espécie seja a dominante. Temos aí a criação de uma mega organização (Orquídea) com o objetivo de frear o aumento populacional dessa espécie. Então, há um esforço por parte de alguns cientistas que estão preocupados para fazer da Ciência uma forma de dominação sobre a outra espécie.

Do outro lado, temos alguns simpatizantes da causa, que são os cientistas (mutantes e humanos) que buscam entender a evolução e a convivência dessa nova espécie. Nisso se cria um cenário proposto pelo Professor X movido pela troca da ciência mutante pela aceitação da nova nação (as drogas produzidas na Ilha pelos mutantes se mostram um como um enorme avanço científico aos humanos). As revistas polarizam essa troca de informações entre as espécies, pois de um lado temos a ciência comum humana e de outro, a nova ciência mutante e em ambas as ocasiões elas têm suas distinções eufóricas e disfóricas para ambas as espécies. O resultado desses conflitos sempre culmina em dois únicos desfechos: a extinção de uma espécie e o desastre global para ambas as espécies. A partir dessa discussão, podemos determinar os polos temáticos da minissérie.

A Sequência Didática tem como tema "Ecossistemas e Relações ecológicas" e é voltada para turmas de $7^{\circ}$ ano do Ensino Fundamental (ver Quadro 4).

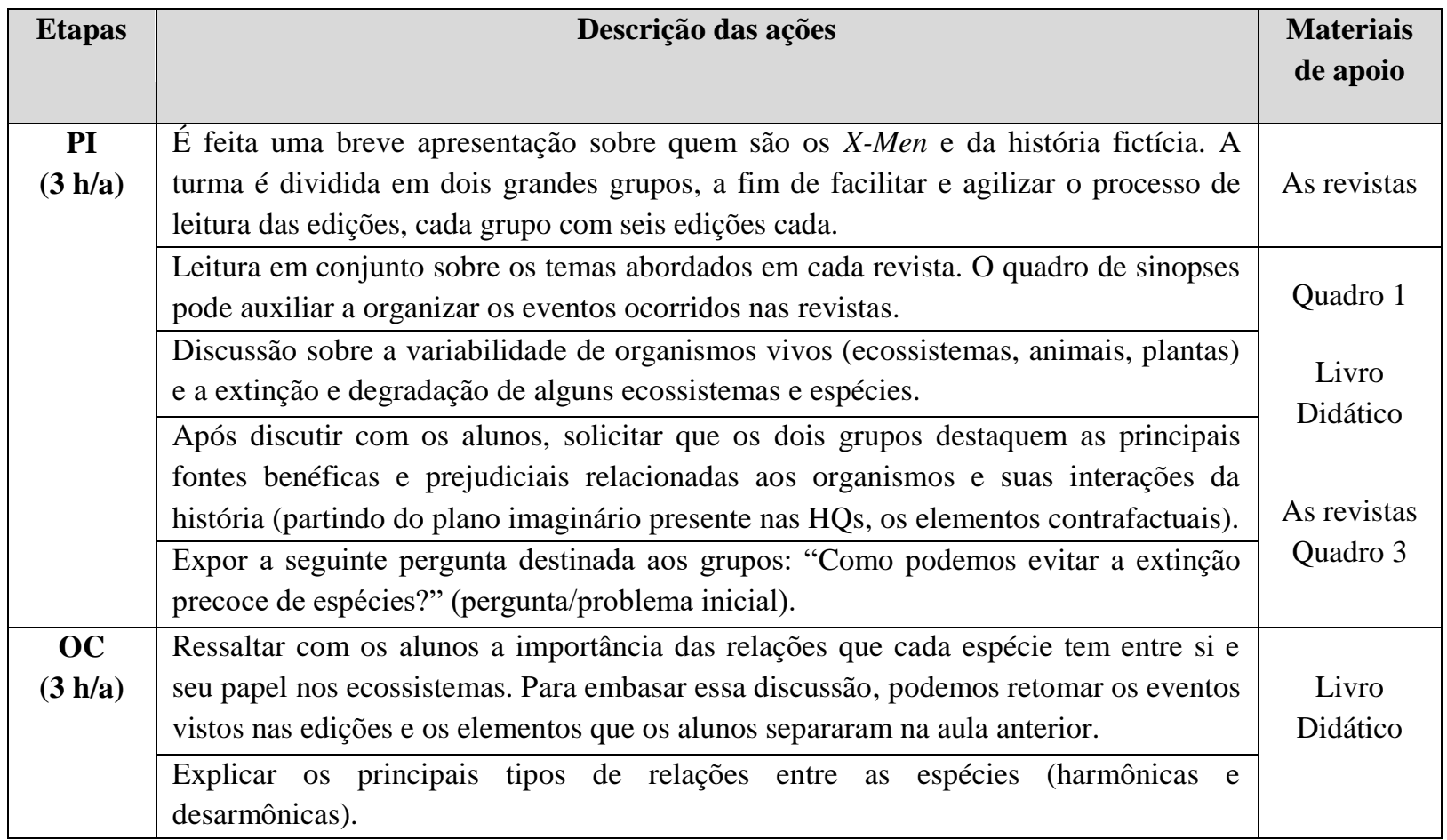




\begin{tabular}{|c|l|c|}
\hline & $\begin{array}{l}\text { Identificar as tecnologias como causa e contenção de danos causados aos } \\
\text { ecossistemas e suas espécies. Os elementos identificados pelos alunos e aqueles } \\
\text { presentes no Quadro 4 podem ser usados para expor os predicados de cada elemento, } \\
\text { partindo do plano imaginário como potenciais solucionadores de problemas. }\end{array}$ & Quadro 4 \\
\hline AC & Retomar o problema inicial derivando para outros contextos, além das HQs. & -- \\
\cline { 2 - 3 }$(\mathbf{2} \mathbf{~ h / a )}$ & Avaliação da aprendizagem. & -- \\
\hline
\end{tabular}

Quadro 4. Proposta de sequência didática proposta a partir da análise das HQs analisadas.

Fonte. SOUSA JUNIOR, 2020.

$\mathrm{O}$ ano foi definido a partir de consulta aos Objetos de Conhecimento e respectivas habilidades presentes no Documento de Orientação Curricular do Estado do Rio de Janeiro (RIO DE JANEIRO, 2019). A sequência foi dividia em três momentos, totalizando 8 (oito) horas/aulas (h/a) (cada aula com 50 minutos), que cobririam duas semanas de aulas da disciplina Ciências nas escolas estaduais do RJ. São apresentados recursos que podem ser usados como material de apoio.

A Problematização Inicial (PI) começa com uma apresentação e o contato com as revistas. Entendemos ser necessária uma hora/aula inteira dedicada a introduzir o tema das aulas junto das revistas e a criação dos dois grupos devido à possível agitação dos alunos ao conhecerem as HQs. Ainda nesta primeira etapa, coloca-se uma questão, a fim de ter um conhecimento prévio sobre o que eles entendem por "biodiversidade". Neste primeiro momento, o questionamento e a rápida apresentação sobre as revistas, junto de uma breve história sobre a equipe de heróis conhecida por X-Men, têm como objetivo introduzir os alunos ao plano imaginário da Ficção Científica presente nas revistas. Ao longo das eventuais leituras, será fácil a comparação com diversos aspectos presentes no dia a dia dos alunos, tais como o convívio entre diferentes espécies, por exemplo. A cultura de super-heróis em si pode ser outro fator a ser explorado, uma vez que eles tendem a gostar deste tipo de gênero literário que não se limita apenas às revistas impressas em paralelo a isso.

Após essa introdução, propõe-se a criação de dois grandes grupos: um chamado "Dinastia" e o outro chamado "Potências". O objetivo da criação de tais grupos é permitir que todos os alunos acessem o material fazendo com que o processo de leitura se torne mais interativo e ágil. Como se trata de duas minisséries que se interligam formando uma saga, cada grupo recebe o nome de sua respectiva parte (Dinastia X e Potências de X), logo, cada um deles é subdividido e os membros de cada grupo realizará a leitura das seis revistas. Podese usar como ferramenta de auxílio as sinopses de cada edição (Quadro 1) para relembrar e 
organizar os fatos ocorridos em cada revista, assim, cada grupo de alunos terá uma visão conjunta sobre a interligação dos eventos. Dá-se início à discussão sobre os ecossistemas e sua biodiversidade expondo os principais fenômenos biológicos e sociais, assim como a importância de cada organismo. Ressalta-se que a revista apresenta diversas passagens entre os diferentes ecossistemas de Krakoa. Podemos dar início aqui à discussão dos principais fatores bióticos e abióticos, definindo os ecossistemas aquáticos e terrestres junto dos componentes individuais e coletivos que contribuem para essa definição, as comunidades e populações presentes dentro desses ecossistemas e todas as suas interações, sejam eles inteiramente terrestres ou não, como florestas, desertos e campos, ou aquáticos, como rios, mares e oceanos. Com isso, pode-se discutir que, ao abalarmos essa harmonia, uma série de prejuízos pode ocorrer, resultando em catástrofes ecológicas e a migração ou extinção de espécies.

É proposta uma atividade inicial para a turma: a identificação e catalogação dos principais fatores prejudiciais e benéficos causado aos seres das HQs. Pode-se trabalhar a extrapolação do plano imaginário, mais precisamente os paralelos e as contraposições dos aspectos reais e fictícios, no qual os alunos podem observar como tais fatores ajudam ou prejudicam as espécies. Aqui, podemos citar alguns exemplos que as revistas nos apresentam, como: o uso das máquinas e outras armas para a degradação de uma espécie ou dizimação de um ecossistema, quais fatores bióticos e abióticos são necessários para a manutenção da vida e como o ambiente e seus recursos naturais podem ser usados em prol do benefício ou malefício entre as espécies. Tendo o auxílio do Quadro 2, podemos destacar e focar nos diversos elementos potenciais que as revistas possuem. Aqui, se apresenta a situação problema: a possível extinção de uma espécie devido a ações irresponsáveis. Dessa forma, é exposta a pergunta: “Como podemos evitar a extinção precoce de espécies?”. As ideias de respostas são recolhidas para análise e comparação com a atividade proposta no último momento da sequência.

$\mathrm{Na}$ Organização do Conhecimento (OC), que compreende o período de 3 horas/aulas, ressaltamos com os alunos a importância das relações que as espécies têm entre si e seu papel nos ecossistemas. Salienta-se que a associação com conteúdos vistos em outras disciplinas também pode ser explorada, como os tipos de relevo em Geografia, uma vez que a Ilha de Krakoa apresenta diversos tipos de relevo ao longo das edições, bem como alguns superpoderes, como o voo ou a supervelocidade, poderiam ser usados em aulas de Física ou Matemática para exemplos de grandezas escalares. Podemos retomar os eventos vistos nas 
revistas, assim como os elementos que os alunos destacaram. Neste momento, entramos nas relações entre espécies, tanto da mesma espécie (relações intraespecíficas) quanto de espécies distintas (relações interespecíficas). Essas relações podem ser harmônicas, quando não há prejuízo para nenhum dos indivíduos envolvidos, ou desarmônicas, quando pelo menos um se prejudica; para abordagem de tal tópico, o Livro Didático é recomendado. As revistas exemplificam várias vezes esses tipos de relações, um deles, de relação interespecífica desarmônica, é o momento em que o vilão Magneto declara guerra aos humanos ao atentar a Casa Branca, nos Estados Unidos. Em outros momentos, essa relação desarmônica não chega a ser tão extrema, como no caso da prisão do mutante conhecido como "Dentes de Sabre", sendo julgado por uma corte inteiramente humana sem nenhum direito a defesa. Por outro lado, as revistas também nos mostram diversos momentos em que as relações interespecíficas e intraespecíficas são harmônicas. Um exemplo claro de tal relação é o trabalho na Ilha de Krakoa, que é uma sociedade por si só, onde há organismos da mesma espécie que trabalham juntos de modo cooperativo, com uma divisão de trabalho organizada. Os mutantes que habitam os terrenos da ilha são inquilinos dela, o que pode caracterizar outro tipo de relação, o inquilinismo.

Outras relações começam a ser vistas nos momentos finais da saga, como, por exemplo, a união entre os heróis e vilões, destacando que estes são indivíduos da mesma espécie que por muito tempo se confrontavam entre si em busca de territórios e dominação. A partir deste momento, esse cenário muda e começamos a identificar os indivíduos da mesma espécie trabalhando juntos em busca de um benefício mútuo. Além disso, a própria ilha que, apesar de possuir diversas habilidades, é inteiramente dependente de seu ecossistema e suas espécies dentro de seu terreno, o que caracteriza uma relação de mutualismo.

O objeto de conhecimento seguinte consiste no uso das novas tecnologias como potenciais solucionadores dos problemas causados pela degradação dos ecossistemas, assim como a manutenção de recursos essenciais do ambiente, como a água (os polos temáticos podem orientar esse tipo de abordagem). Nas revistas, somos apresentados aos sistemas de Krakoa, criado pelo mutante Cifra em parceria com a própria Ilha Krakoa, através do idioma krakoano. Os mutantes que habitam a ilha podem entender essas ferramentas tecnológicas graças ao idioma, a fim de trabalharem em conjunto para a manutenção e preservação do ecossistema da ilha. A ilha é um organismo vivo que se identifica como fauna, logo, ela própria e Cifra conseguem se comunicar e essa comunicação abre espaço para o surgimento de diversas tecnologias mutantes e humanas, como a criação de uma base de monitoramento 
que cuida do tráfego de indivíduos que entram e saem da ilha, assim como o acompanhamento de recursos fornecidos pela ilha, no intuito de que nunca possam extrair mais do que pode ser resposto ao ecossistema, tais como as flores ou árvores. Para esta abordagem, o professor pode utilizar o Quadro 4, no qual estão expostos os elementos e seus predicados, permitindo uma aproximação lúdica e palpável dos alunos em enxergar esses problemas e soluções, afinal, nas histórias temos o uso de diversas tecnologias que vão de encontro aos problemas causados, exercendo um potencial de solução. Pode-se também complementar os elementos destacados pelos alunos que apareceram ou não no Quadro 3.

Por fim, na Aplicação do Conhecimento (AC) que compreende o período de 2 horas/aula, retomamos a pergunta inicial: "É possível evitar a extinção precoce de espécies?" Após a introdução das histórias fictícias e as possíveis conexões feitas pelos próprios alunos a respeito do mundo real, seus problemas e possíveis soluções, aqui podem ser expostos os polos temáticos da obra (Figura 2), auxiliando o professor a explorar as diferentes perspectivas sobre a ciência e a tecnologia na obra de Ficção Científica para fazer um paralelo com o real, a fim de criar uma atividade avaliativa dos grupos. Essa atividade consiste na criação de dois trabalhos, um para cada grupo, em que cada grupo terá que elaborar uma iniciativa propondo ideias que possivelmente evitem a extinção precoce de alguma espécie. Dentro desse trabalho, os alunos terão que incluir pelo menos um ecossistema e dizer como as relações entre eles (o meio e os indivíduos que ali habitam) funcionam e o que seria feio para evitar sua degradação e a possível extinção das espécies ali presentes.

São propostas duas maneiras de elaborar este trabalho: a primeira consiste em uma breve apresentação em formato de seminário e a segunda, na criação de uma HQ feita pelos próprios alunos. Acredito que esse ponto seja muito importante, pois, ao considerarmos o aluno o centro da aula, temos que ficar atentos aos diferentes gostos e preferências por parte dos estudantes e oferecer a possibilidade de escolha pode ser um diferencial. Aqui se torna possível a aplicação dos conceitos por parte dos alunos sobre a biodiversidade (os humanos, mutantes e a Ilha de Krakoa), os ecossistemas e suas peculiaridades e bens essenciais (A flora única de Krakoa, seu potencial uso as espécies que habitam ou não a ilha, a criação de uma nação), a interação entre as espécies (relação entre os humanos e mutantes) de maneira harmônica ou desarmônica, o uso da tecnologia de maneira responsável ou irresponsável e suas consequências. Todos identificados e estudados no momento anterior. 


\section{CONSIDERAÇÕES FINAIS}

Em vista do que foi dito, a realização desta pesquisa permitiu uma reflexão sobre o potencial uso das Histórias em Quadrinhos de super-heróis e a Ficção Científica no ensino de Ciências. A análise das minisséries em questão mostrou a potencialidade de seu uso em uma Sequência Didática que permitiu a contemplação de conceitos científicos voltados ao estudo de Ecossistemas e Relações Ecológicas. Com isso, foram incluídos temas sociais relacionados à biodiversidade, degradação ambiental, entre outros. Apesar das HQs de super-heróis estarem no gosto de crianças e adolescentes, existe a questão de falta de acesso imediato a estes materiais, uma vez que estes, em sua maioria, são produtos importados dos Estados Unidos, salientando que a chegada do material junto de sua tradução ao idioma brasileiro e principalmente o preço atualmente elevado das revistas são alguns fatores que acabam prejudicando o acesso e a inclusão a estes acervos em potencial. Por isso, trabalhar com as HQs em sala de aula pode se mostrar um processo um pouco desafiador em turmas maiores, por exemplo, pois essa prática pode ser frustrada pela falta de revistas disponíveis para todos os alunos, seja pelo alto preço de cada edição ou pela disponibilidade das edições em nosso idioma. São diversas as atividades que as HQs podem trazer para a sala de aula, seja como meio para incentivar a leitura, para desenvolver a criatividade, a imaginação ou a compreensão de conceitos científicos, e podem contribuir também para a mudança de comportamento de alguns alunos, fazendo com que eles questionem, participem das aulas e, por meio de sua leitura, participem mais ativamente das discussões. A riqueza e variação de detalhes nas HQs possibilita que os conteúdos, antes abstratos, se tornem mais palpáveis, além de estimular e despertar a vontade de aprender do estudante.

O uso das HQs na Sequência Didática se mostrou válida por diversos fatores: estímulo ao interesse dos estudantes pela leitura e conhecimento, praticidade da utilização, a verbovisualidade característica das HQs e uma nova alternativa de recurso complementar. De encontro a isso, Piassi e Pietrocola (2009) enfatizam que a Ficção Científica contribui justamente na possibilidade de se discutir - sem compromisso com o factual - não o que foi, mas o que poderia ter sido e o que poderia vir a ser. Atividades deste tipo podem ser um instrumento adequado para a introdução de elementos vistos nas aulas de Ciências partindo de questões atuais e das preocupações futuras e trabalhando com a imaginação criativa. Apesar dos diversos benefícios que as HQs podem trazer para o ensino de Ciências, por se tratar de 
um material que desperta curiosidade, destacamos que elas devem ser consideradas como um recurso complementar, podendo ser associada a outros recursos didáticos.

\section{REFERÊNCIAS}

ABREU, S. E. A. Pesquisa e Análise Documental. In: IV Jornada de Educação e Ciências Sociais I Encontro de Egressos do ISE - Profissão Professor na Contemporaneidade: desafios e perspectivas. Goiás, 2008.

ALBUQUERQUE, I. C. T. C.; RAMOS, M. B. Heróis e vilões: as mídias de ficção científica no ensino de radiações. In: Anais... X Encontro Nacional de Pesquisa em Educação em Ciências, São Paulo: ABRAPEC, 2015. Disponível em:

http://www.abrapecnet.org.br/enpec/x-enpec/anais2015/resumos/R1756-1.PDF. Acesso em 13 ago. 2021.

DELIZOICOV, D; ANGOTTI, J. A.; PERNAMBUCO, M. M. C. A. Ensino de Ciências: fundamentos e métodos. São Paulo: Cortez, 2002.

FLICK, U. Qualidade na pesquisa qualitativa. Coleção Pesquisa Qualitativa. Porto Alegre: Artmed, 2009.

KRAKHECKE, C. A. Representações da guerra fria nas histórias em quadrinhos BATMAN - O Cavaleiro das Trevas e Watchen (1979-1987). 145f. Dissertação (Mestrado em História). Porto Alegre: PUC-RS, 2009. Disponível em:

http://tede2.pucrs.br/tede2/handle/tede/2313. Acesso em 13 ago. 2021.

MARVEL COMICS. X-MEN: Dinastia X, v. 1 a 6. São Paulo: Panini Comics, 2020a.

MARVEL COMICS. X-MEN: Potências de X, v. 1 a 6. São Paulo: Panini Comics, 2020 b.

MENDONÇA, J. R. C.; CORREIA, M. A. L. A abordagem dramatúrgica e os métodos visuais de pesquisa: a observação do gerenciamento de impressões nas interações sociais. Revista de Administração Mackenzie, v. 9, n. 4, p. 125-141, 2008. Disponível em: https://www.scielo.br/j/ram/a/5FfSXqMZjxPGMFNGthNT6SM/?format=pdf\&lang=pt. Acesso em 13 ago. 2021.

NASCIMENTO JR., F. A.; PIASSI, L. P. Um estudo do potencial didático das histórias em quadrinhos de ficção científica para o ensino de física. In: Anais... VIII Encontro Nacional de Pesquisa em Educação em Ciências, Campinas, 2011. Disponível em:

http://abrapecnet.org.br/atas_enpec/viiienpec/resumos/R0678-1.pdf. Acesso em 13 ago. 2021.

\section{OLIVEIRA, M. M. Sequência didática interativa no processo de formação de} professores. Petrópolis, RJ: Vozes, 2013.

PIASSI, L. P. A ficção científica e o estranhamento cognitivo no ensino de ciências: estudos críticos e propostas de sala de aula. Ciência \& Educação, v. 19, n. 1, p. 151-168, 2013. Disponível em: 
https://www.scielo.br/j/ciedu/a/JBTtMYnbjfQKzCZfNty9Cgh/?lang=pt\&format=pdf. Acesso em 13 ago. 2021.

PIASSI, L. P. C. Contatos: A ficção científica no ensino de ciências em um contexto sócio cultural. 453f. Tese (Doutorado em Educação). São Paulo: FE/USP, 2007. Disponível em: https://www.teses.usp.br/teses/disponiveis/48/48134/tde-10122007110755/publico/TeseLuisPauloPiassi.pdf. Acesso em 13 ago. 2021.

PIASSI, L. P. O Segredo de Arthur Clarke: Um Modelo Semiótico para Tratar Questões Sociais da Ciência Usando a Ficção Científica. Ensaio - Pesquisa em Ensino de Ciências, v. 14, n. 1, p. 209-226, 2012. Disponível em: https://www.scielo.br/j/epec/a/vKbRzbNZMWcmr84X4LHGBvp/?lang=pt\&format=pdf. Acesso em 13 ago. 2021.

PIASSI, L. P.; PIETROCOLA, M. Ficção científica e ensino de ciências: para além do método de 'encontrar erros em filmes'. Educação e Pesquisa, v. 35, n. 3, p. 525-540, 2009. Disponível em: https://www.scielo.br/j/ep/a/dLJHkBSMQHQ4YYhZQmPNT5s/?lang=pt\&format=pdf. Acesso em 3 ago. 2021.

RIO DE JANEIRO (Estado). Secretaria da Educação. Documento de Orientação Curricular do Estado do Rio de Janeiro. Rio de Janeiro: SEEDUC, 2019. Disponível em: https://undime.org.br/uploads/documentos/phpOu2TkQ_5ddd5f2879044.pdf. Acesso em 13 ago. 2021.

ROSA, F. Almanaque dos quadrinhos: 120 anos de história. São Paulo: Discovery Publicações, 2014.

SANTOS, M. O.; GANZAROLLI, M. E. Histórias em quadrinhos: formando leitores. TransInformação, v. 23, n. 1, p. 63-75, 2011. Disponível em: https://www.scielo.br/j/tinf/a/D9KdmXLWyZcPhMcvH5cgpSg/?lang=pt\&format=pdf. Acesso em 13 ago. 2021.

SIANI, M. V. B. Alegorias da diferença: valores, estigma e segregação social nos quadrinhos X-Men. 150f. Dissertação (Mestrado em Sociologia) - Instituto de Filosofia e Ciências Sociais, Universidade Federal do Rio de Janeiro, Rio de Janeiro, 2003.

SILVA, D. A. B. Contribuições da Ficção Científica para a Educação CTS no contexto da formação inicial de professores de Ciências e Biologia. 268f. Dissertação (Mestrado em Ensino de Ciências, Ambiente e Sociedade). São Gonçalo: FFP/UERJ, 2019. Disponível em: https://drive.google.com/file/d/1iLIxIt9QW6ys5D10nWHoF7ieNLby8fuB/view. Acesso em 13 ago. 2021.

SOUSA JUNIOR, J. A ficção científica em histórias em quadrinhos: potenciais para o ensino de ciências. 81f. Trabalho de Conclusão de Curso (Graduação em Ciências Biológicas). São Gonçalo: FFP/UERJ, 2020. 
THOMPSON, J. B. Ideologia e cultura moderna: teoria social critica na era dos meios de comunicação de massa. 5. ed. Petrópolis: Vozes, 2000. Disponível em:

https://periodicos.unb.br/index.php/les/article/view/4421/4034. Acesso 13 ago 2021.

VIEIRA, L. B. G; FERNANDES, G. W. R; MALDANER, O. A; MASSENA, A. P. Situação de estudo: o que vem sendo publicado em eventos e periódicos da área de ensino de ciências?. Ensaio - Pesquisa em Educação em Ciências, v. 20, e2914, p. 1-29, 2018. Disponível em: https://www.scielo.br/j/epec/a/7Gdndd9yhYGN3cq8HJ7CTvk/?format=pdf\&lang=pt. Acesso 13 ago. 2021.

XAVIER, G. K. R. S. Histórias em quadrinhos: panorama histórico, características e verbovisualidade. Revista Darandina, v. 10, n. 2, p.1-20, 2017. Disponível em: https://www.ufjf.br/darandina/files/2018/01/Artigo-Glayci-Xavier.pdf. Acesso 13 ago. 2021.

\section{APÊNDICE 1}

\section{AGRADECIMENTOS}

Não se aplica.

\section{FINANCIAMENTO}

Não houve financiamento.

\section{CONTRIBUIÇÕES DE AUTORIA}

Resumo/Abstract/Resumen: Luciano Calixto de Sousa Junior e Tatiana Galieta Introdução: Luciano Calixto de Sousa Junior e Tatiana Galieta Referencial teórico: Luciano Calixto de Sousa Junior e Tatiana Galieta Análise de dados: Luciano Calixto de Sousa Junior

Discussão dos resultados: Luciano Calixto de Sousa Junior e Tatiana Galieta Conclusão e considerações finais: Luciano Calixto de Sousa Junior e Tatiana Galieta Referências: Luciano Calixto de Sousa Junior e Tatiana Galieta Revisão do manuscrito: Kamila Nogueira Peixoto Aprovação da versão final publicada:

\section{CONFLITOS DE INTERESSE}

Os autores declararam não haver nenhum conflito de interesse de ordem pessoal, comercial, acadêmico, político e financeiro referente a este manuscrito.

\section{DISPONIBILIDADE DE DADOS DE PESQUISA}

O conjunto de dados que dá suporte aos resultados da pesquisa foi publicado no próprio artigo.

\section{CONSENTIMENTO DE USO DE IMAGEM}

Não se aplica.

\section{APROVAÇÃO DE COMITÊ DE ÉTICA EM PESQUISA}

Não se aplica.

\section{COMO CITAR - ABNT}

SOUSA JUNIOR, Luciano C.; GALIETA, Tatiana. Histórias em quadrinhos e ficção científica: análise e proposta de uso no ensino de ciências. REAMEC - Rede Amazônica de Educação em Ciências e Matemática. Cuiabá, v. 9, n. 3, e21093, set./dez., 2021. http://dx.doi.org/10.26571/reamec.v9i3.12870. 
COMO CITAR - APA

Sousa Junior, L. C. \& Galieta, T. (2021). Histórias em quadrinhos e ficção científica: análise e proposta de uso no ensino de ciências. REAMEC - Rede Amazônica de Educação em Ciências e Matemática, 9 (3), e21093. http://dx.doi.org/10.26571/reamec.v9i3.12870.

\section{LICENÇA DE USO}

Licenciado sob a Licença Creative Commons Attribution-NonCommercial 4.0 International (CC BY-NC 4.0). Esta licença permite compartilhar, copiar, redistribuir o manuscrito em qualquer meio ou formato. Além disso, permite adaptar, remixar, transformar e construir sobre o material, desde que seja atribuído o devido crédito de autoria e publicação inicial neste periódico.

\section{DIREITOS AUTORAIS}

Os direitos autorais são mantidos pelos autores, os quais concedem à Revista REAMEC - Rede Amazônica de Educação em Ciências e Matemática - os direitos exclusivos de primeira publicação. Os autores não serão remunerados pela publicação de trabalhos neste periódico. Os autores têm autorização para assumir contratos adicionais separadamente, para distribuição não exclusiva da versão do trabalho publicada neste periódico (ex.: publicar em repositório institucional, em site pessoal, publicar uma tradução, ou como capítulo de livro), com reconhecimento de autoria e publicação inicial neste periódico. Os editores da Revista têm o direito de proceder a ajustes textuais e de adequação às normas da publicação.

\section{PUBLISHER}

Universidade Federal de Mato Grosso. Programa de Pós-graduação em Educação em Ciências e Matemática (PPGECEM) da Rede Amazônica de Educação em Ciências e Matemática (REAMEC). Publicação no Portal de Periódicos UFMT. As ideias expressadas neste artigo são de responsabilidade de seus autores, não representando, necessariamente, a opinião dos editores ou da referida universidade.

\section{EDITOR}

Patrícia Rosinke (D) 9

\section{HISTÓRICO}

Submetido: 17 de agosto de 2021.

Aprovado: 12 de setembro de 2021.

Publicado: 08 de novembro de 2021. 